\title{
Maritime Airborne Noise: Ships and Harbours
}

The topic of ships as noise sources has been studied for decades, mainly as regards underwater sound emission and onboard noise. There are several reasons: (1) underwater noise is investigated for military purposes in terms of "acoustic signatures" - a combination of elements (mainly cavitation noise, machinery noise and hydrodynamic noise) that help identify and track a vessel or weapon, (2) short and longterm negative effects on marine fauna, in particular marine mammals and cephalopods and (3) continuous onboard noise that can have an adverse impact on human health for both passengers and crew. Considering this last reason, from a regulatory point of view, the International Convention for the Safety of Life at Sea (SOLAS) in its regulation II-1/3-12 requires ships to be compliant with the International Maritime Organization (IMO) resolution MSC.337(91) "Code on noise levels on-board ships". This IMO resolution is nowadays mandatory for ships of 1,600 gross tonnage or more, which have to be constructed to protect workers from noise and to reduce shipboard noise.

The airborne noise radiated from the ship to the external environment should be discussed separately. The reason why a ship is not usually characterized as a noise source like every other kind of transportation vehicle (e.g. cars, trucks, trains, airplanes, etc.) can be found in the fact that their complexity and their dimensions make it difficult and challenging to describe the acoustical field in their surroundings.

The Directive 2002/49/EC of the European Parliament and of the Council of 25 June 2002 relating to the assessment and management of environmental noise does not have specific requirements for harbour noise. These are included in the context of industrial noise without taking into account the peculiar aspects of such realities, such as complex sound sources (ships, cranes, etc.), their distribution and the particular characteristics of propagation (e.g. over bodies of water).

In recent years, some efforts have been made in order to face this problem. Within the EU FP7 Project SILENV (Ships oriented Innovative soLutions to rEduce Noise \& Vibrations), models of different ships (a fishing research vessel and a multipurpose ship) were developed by means of ray-tracing software and validated by experimental data. The sound field was then numerically studied for an urban area in the surroundings of the harbour.

SILENV had a positive impact on the perception of these issues, that has subsequently been addressed for example by ship classification societies. In January 2019, Lloyd's Register launched the first ever airborne noise notation for ships in harbours, and a procedure was introduced to define a standard to control ship airborne noise emissions. In this way, ports are assisted in the knowledge of the noise impact of the ships that are transiting or docking, and allows counter-measures to be taken if these ships are expected to annoy the surrounding residential areas.

After a few months, DNV GL developed another voluntary class notation for ship environmental airborne noise called QUIET. This will be useful for both port authorities and shipowners, which can, for example, lead to payment of lower port fees.

Moreover, the World Port Sustainability Program developed by the International Association of Ports and Harbours aims to include in 2020 the ships' external airborne noise in an Environmental Ship Index, that already has over 7,000 ships on its register.

In the light of all this, it is therefore understandable that the European Union is conducting a research towards the control of harbour noise emissions. Several projects were recently financed and are continuing. Projects include: REPORT, RUMBLE, DECIBEL, MON ACUMEN, L.I.S.T. Port and TRIPLO within the cross-border Interreg Italy-France Maritime 20142020 Programme. ANCHOR LIFE project, in the framework of the LIFE Programme, has partners from Italy, Greece and Spain.

All of these projects aim to tackle the issues of port noise from different points of view. They range from installing monitoring infrastructures to applying sound absorbing asphalt, from integrated intelligent transportation systems for traffic management to cold ironing, from shared databases for sources and activities to the development of a numerical simulation model for port noise. The common final goal of this cluster of projects is the creation of calculation algorithms, rewards schemes, best practices and guidelines. They will allow to achieve a significant improvement in the understanding, the management and the monitoring of port noise.

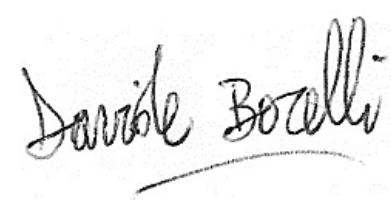

Davide Borelli

Associate Editor, IJAV 